\title{
Emotional Intelligence and Health Outcomes
}

\author{
Leehu Zysberg \\ Gordon College of Education, Haifa, Israel \\ Email: leehuzysberg@yahoo.com
}

How to cite this paper: Zysberg, L. (2018) Emotional Intelligence and Health Outcomes. Psychology, 9, 2471-2481. https://doi.org/10.4236/psych.2018.911142

Received: September 3, 2018

Accepted: October 9, 2018

Published: October 12, 2018

Copyright $\odot 2018$ by author and Scientific Research Publishing Inc. This work is licensed under the Creative Commons Attribution International License (CC BY 4.0).

http://creativecommons.org/licenses/by/4.0/

\begin{abstract}
This paper presents the relatively novel concept of Emotional Intelligence (EI) within the context of health care and health outcomes. The paper uses the available literature to present what is already known, describe emerging trends and highlight what is still unknown, regarding the role of EI in determining various health outcomes. The author offers an interpretive analysis of the existing evidence and presents a preliminary explanatory model of the association between EI and various health outcomes. The model is discussed, and directions for future studies and applications are presented.
\end{abstract}

\section{Keywords}

Emotional Intelligence, Health, Health Outcomes, Emotion Regulation, Health Psychology, Emotions, Stress, Anxiety

\section{Introduction}

Science has always treated the study of emotions with ambivalence: On one hand evidence has supported the major role emotions and emotional experiences play in a broad range of settings, and on the other hand emotions were considered amorphous concepts, belonging more in the realm of philosophy and art than in science (Sternberg, 2001). A generally agreed upon definition of emotion suggests that the concept represents multi-systemic response patterns (physiological, motivational and perceptual) preparing organisms for action (Sternberg, 2001; Zysberg, 2017). Emotions are basically categorized as appetitive (positive, rewarding) and aversive (negative, undesirable) and as such they provide individuals with a basic "behavioral auto-pilot" for survival. This mechanism underlies coping with threat or making the most of opportunities. Thus anger or frustration responses are typically aimed at ridding ourselves of threats or obstacles, fear responses are geared toward putting as much distance as possible between us and a potential threat 
while love or attraction usually entails keeping, or preserving a valued object or person (Nesse, 1990). This response pattern, however, takes its toll on our resources in a world that no longer boils down to "fight-or-flight" behaviors. Here's why.

Emotional reactions seem to be designed to guide our responses and actions in situations requiring swift reaction and actions: An emergency requiring a decisive fight or flight response, attachment-related emotions geared toward self, and others' preservation (Morris \& Bromhall, 1994). What characterizes most of these instances is that they are fleeting moments, requiring a momentary recruitment of resources toward action. Modern life, however, sets new challenges to us, but our emotional navigator cannot really tell the difference between a lion charging or an angry boss at work or even a marital crisis (Johnston, 1999; Zysberg, 2017). While all the above can be referred to as threats, the first takes only a few moments (for better or worse), while the others may describe long-term conditions. This is where emotions may take an even more important role, since most of us are exposed to conditions that are on-going in nature, evoking long-term emotional responses.

How effectively we use our emotions and manage them may be a pivotal process underlying our understanding of how emotions associate with various health outcomes. The recently presented concept of Emotional Intelligence (EI) offers both a missing link and an organizing framework in our understanding of pathways leading from emotions and emotional experiences to health. While theories of emotional intelligence offer various conceptualizations of the idea: either as personality trait (Petrides, \& Furnham, 2001) or as a human ability (Mayer, Roberts, \& Barsade, 2008), a branch of general mental ability, the various model share a core definition that can be agreed upon: The concept describes a group of human potentials allowing individuals to identify emotions, integrate emotional information in thought and problem solving, understand complex emotional situations and manage emotional experiences and displays in an adaptive manner. Simply put emotionally intelligent individuals are capable of identifying their own and others' emotions, and can manage them more effectively.

Research on EI and its associations with various criteria is still in its infancy, however at this point enough evidence has been accumulated to give the concept credence as a predictor of human performance in various fields (e.g.: education, job performance, see: Khalili, 2012; Mayer, Roberts, \& Barsade, 2008). A relatively new body of research looks into the concept's relevance within the field of health. While the study of emotional intelligence and health is still taking baby steps forward, enough evidence has presented itself to serve the purpose of this paper: 1 . Provide an interpretive analysis of the evidence to the association between EI and various indices of health outcomes, and.2. Based on the analysis, propose a working model accounting for these associations to guide future studies as well as practice. 


\section{Methodology}

\subsection{Design and Settings}

This paper presents an interpretive analysis of literature drawn from empirical and theoretical papers to propose a working model accounting for the assocations between measures of EI and health outcome indices.

\subsection{Data and Materials}

Two academic search engines were used to identify papers concerning the EI-health association (PsycInfo and Google Scholar) using the keywords: emotional intelligence and health, mental health, physical health. The search yielded over 1,840,000 results, however after filtering results for duplicate copies, non-empirical or non-peer-reviewed sources, only 96 sources were included in the preliminary data pool. This pool served as a sampling frame for the literature review in this paper. Not all 96 papers are reviewed here since systematic reviews of the literature and meta-analysis are already in existence (albeit not necessarily up to date, see Martins et al., 2010). Only representative empirical studies or meta analyses with theoretical added value were included in the current selective review and analysis.

\subsection{Procedure}

The literature was reviewed and content analyzed by 2 scholars with deep knowledge of the theory and empirical research around EI. They searched for common themes and trends in definitions and findings, and where no initial agreement was reached, they discussed the evidence until consensus was reached, The results of the analysis include: Working definitions of EI and its relevance to the context of health research and practice, presentation and analysis of the associations between EI measures and health indices and finally-an emerging explanatory model is presented and discussed.

\section{Results}

\subsection{What Is Emotional Intelligence?}

As with most concepts making their first steps in the scientific arena, EI too has known some debate and controversy: Notions of social and emotional abilities being an integral part of human potentials and abilities go as far back as the early $20^{\text {th }}$ century (e.g.: Thorndike's early depictions of intelligence as comprising of both scholastic and social intelligences, see: Thorndike, 1920). However such notions quickly lost center stage to others focusing on cognitive aspects of intelligence and human abilities. Add to that the rise of information systems as of the late 1950s, and you'd see how the study of emotions in the context of human potentials and abilities lost favor (Gustafsson, 1984). Emotions, if studied at all at that point in time, were explored more as an intervening factor, a factor in psychopathology and so forth. However, the scientific community could not ignore 
an increasing stream of evidence suggesting emotions do play a major role in shaping our perceptions, interpretation of realities and actions not only in a negative manner (i.e.: biasing decision-making or modifying perception processes as often offered by classic studies of cognition, see for example: Leventhal \& Scherer, 1987) but also as a source of information that can be used to fine-tune and make our decisions, actions and interactions more effective. Moreover it was quite obvious that some people are better at that then others-which meant there is possibly a human potential allowing us to make better or worse use of our emotions. Enter Emotional Intelligence.

It is quite difficult to determine who first coined the term, However it was made popular, even before it was properly explored scientifically by Goleman (1996) using existing evidence to suggest EI is a group of non-cognitive skills allowing individuals to more effectively function in everyday settings. Those skills included: self-awareness and self-regulation, self-motivation, empathy and possessing high social skills. While the concept as well as the model became highly popular, many critics claimed that Goleman merely re-packed existing, well-researched concepts and factors associated with human adaptation and "sold" it to his readers as a new, exciting notion (e.g.: Schutte, Ree, \& Ceretta, 2004).

However, as the science of psychology started to pay more and more attention to the concept, two traditions eventually set roots in empirical research, each envisioning and measuring EI a bit differently:

1) Ability $E I$ is an approach conceptualizing the notion as an equivalent of scholastic intelligence, that is individuals' ability to perceive, process and manage emotional information. They define 4 branches of EI: perceiving/ identifying emotions, integrating emotions into reasoning processes, understanding complex emotions and regulating/ managing emotions, in self and others (Mayer, Caruso, \& Salovey, 1999). This framework also defines the approach to measuring EI, much in line with other ability tests: presenting individuals with tasks requiring correct and effective processing of emotional information and testing their responses against a criterion of effectiveness. While authors are still debating the application of ability testing methodology to EI, the testing methods spawned by this approach are some of the leading in the field in psychometric terms (Brackett \& Mayer, 2003).

2) Trait EI is a different way of looking at EI, this time as a behavioral tendency, defined as a group of personality traits associated with personal and interpersonal flexibility (Petrides \& Furnham, 2001). Components include: adaptability to changes, assertive behavior pattern, emotion perception and regulation, low impulsivity, self-awareness and esteem, empathy, happiness and optimism (Petrides, 2010). As with most concepts in the tradition of personality assessment, measures of trait EI are typically self-report questionnaires allowing individuals to rank typical behavior patterns reflecting the above characteristics (Cooper \& Petrides, 2010). 
These (some say competing and some say complimentary) models both show evidence to support their validity and applicability in various settings, especially in organizational and educational ones (e.g.: Cherniss et al., 2006; Stough, et al., 2009). If you will, regarding the questions of which model is better, or whether at this point we call two distinctly different notions EI, the jury is still out.

\subsection{Emotional Intelligence and Health Outcomes: What We Know}

To date, two comprehensive literature reviews examined the evidence associating EI with various indicators of health outcomes. Both are quite consistent in their findings. Both reviews have divided health outcomes in at least two domains: psychological/psychogenic health outcomes and physiological health outcomes. Both meta-analyses found similar effect sizes averaging 0.35 for the association with psychological health and $0.25-0.27$ for physical health measures (Martins, Ramalho, \& Morin, 2010; Schutte et al., 2007). An additional, recent meta-analysis also lends support to the validity of the associations between EI and various aspects of emotional and psychological well-being (Sanchez-Alvarez et al., 2016). Most of the evidence shows consistent positive associations between measures of EI and criteria for well-being (e.g.: Austin, Saklofske, \& Egan, 2005) and negative associations between EI and measures of stress and anxiety (Landa et al., 2008). Beyond these striking findings we see a moderate yet relatively consistent association between measures of EI (both within the ability and trait traditions) and measures of psychological health (e.g.: depression, distress, etc.) with meager evidence pointing to a weaker yet similar trend vis-à-vis criteria of physical health. Simply put, EI seems to consistently associate with various health outcomes, but how and why? That's another issue that is yet to be thoroughly explored. That being said, there are preliminary pieces of evidence pointing to a few potential models. We'll briefly review two of the leading ones:

\subsection{Emotional Intelligence as an Organizing Framework}

The concept of EI emphasizes the suggestion that emotions contain at least two components that are critical to successful adaptation: 1) Information about our (internal or external) environment, and. 2) Motives to guide behavior. Another assumption underlies most definitions and applications of EI: It posits that individuals vary dramatically in the extent to which they are predisposed and capable of processing their (and others') emotions. This is where it gets interesting: while certain emotional reactions may be more or less similar among different individuals, the way they will understand and process these reactions will vary, and EI offers an explanation as to why and how. Thus, two students who failed an exam will feel frustration. However-the more emotionally intelligent student will understand why he is frustrated, and will be able to channel this emotion to motivate him to study harder for the next exam. 


\subsubsection{EI as an Explanatory Mechanism of Emotional Experiences}

Life events are often associated with (at times severe) emotional reactions and experiences: from a life-threatening diagnosis to the need to adhere to an often unpleasant treatment plan for an existing health condition (e.g: Diabetes). However it is widely acknowledged that individuals respond differently to these experiences. While some are devastated and overwhelmed, others take the experience in stride and may even develop insights and experience personal growth in light of their experiences. Mind you, we are not talking about bottling up emotional reactions but truly experiencing and interpreting them differently-and in a manner that is more conductive to adaptive outcomes. The literature suggests that naming emotions, understanding where they come from and self-regulation, all terms associated with the core characteristics of EI associate with more adaptive interpretations of life situations and more adaptive cognitive and general mental state. In other words: emotional intelligent individuals may experience less emotional distress under stressful conditions and experience more well-being under positive circumstances. As a result they may be less prone to health risk behavior, more likely to adhere to intervention plans and schedules, therefore more likely to experience better health outcomes.

\subsubsection{EI as an Explanatory Mechanism of Emotionally Motivated Behavior}

Emotions are among the most basic and are probably the strongest motives behind our actions and behavior patterns. Happiness, satisfaction, fear or anger feed behaviors, but which behaviors? This is where, theory suggests, EI makes a difference: Emotionally intelligent individuals will be more effective at "recruiting" emotions to their benefit, reacting in a more adaptive manner than their less emotionally intelligent counterparts. Thus, for example, anxiety or stress resulting from a life-threatening diagnosis may lead one individual to change and modify their lifestyle, adopt healthier routines and habits, thus postponing functional decline and extending healthy years, while leading another to self-destructive behavior, substance abuse, depression, etc.

\subsection{An Emergent Model of EI and Health Outcomes}

At this point there is still not enough evidence to support specific paths connecting EI with health outcomes, however preliminary results using physical and psychosomatic health criteria (in these cases: diabetes and eating disorders) emphasize the role of negative emotion and its mitigation as a mediating mechanism in the association between EI and health outcomes, lending some support at least to the latter explanation (Zysberg, 2016; Zysberg, 2017b). The few studies in existence highlight the potential role of stress and its long term derivative-anxiety as potential mediators of the established association of EI-health. The evidence paint a model that may serve as a palette for future research and later implementation, see Figure 1.

The model begins with an environment that presents potential stressors to us on both anecdotal basis (e.g.: a crisis at work) or on a smaller scale, daily 
Life experiences

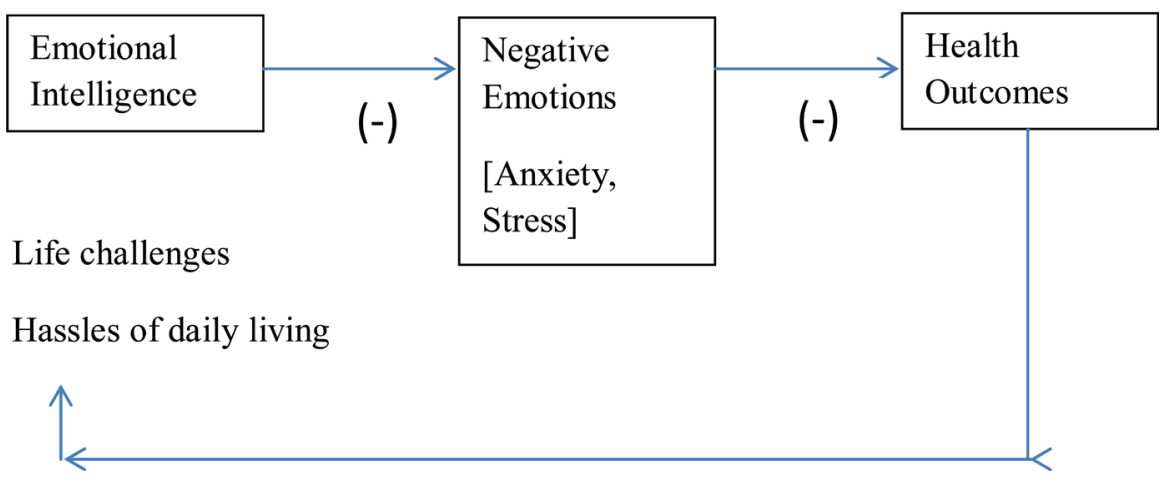

Figure 1. A proposed model of EI and health outcomes.

basis-usually referred to as the hassles of daily living (DeLongis et al., 1982), a concept long associated with health outcomes. The model proposes EI has a protective effect for various health outcomes, as a result of it serving as a resource moderating negative affect or emotions, which in turn negatively associate with health outcomes and indices. In terms of proposed process, EI determines how our emotional reactions to stressors will look like and the toll they will take on us, suggesting that individuals higher in EI will experience less stress, anxiety and other products of potential stressors. Experiencing lower stress and anxiety across extended periods of time, which in turn associates with a broad range of health outcomes (e.g.: Brosschot, Gerin, \& Thayer, 2006; Chiesa \& Serretti, 2009).

The above model may highlight a path that is not exclusive: preliminary evidence suggests that the mediation effect is partial in nature (e.g.: Zysberg, 2017b). EI may have a direct effect on some outcomes while with others additional mediators may play a role that is still unknown to us. Candidates for such potential mediators may be positive emotions, social support, sense of coherence and optimism-often mentioned in the literature as emotion-based factors associated with a broad range of health outcomes (Berkman \& Glass, 2000; Eriksson \& Lindstom, 2006; Mäkikangas, Kinnunen, \& Feldt, 2004).

\section{Discussion}

If indeed $\mathrm{EI}$ is an individual resource that has a protective potential in diverse settings, how can we harness it to promote health related research and practice?

\subsection{Theory and Research around the EI-Health Association}

Firstly additional research is direly needed to better understand the paths through which EI works. More populations should be included in terms of various clinical and non-clinical samples, and cultural differences acknowledged. As researchers and theoreticians further explore this association, better, more reliable and valid as well as shorter, applicable measures of central concepts such as EI, emotion regulation, anxiety and stress may be developed and tested in vari- 
ous settings. While current measures of the discussed concepts are well established in the literature, there might be a need for further adaptation of measures and tools for various settings (e.g.: hospital and other care settings, home and family, work, etc.).

Secondly, while the model presented here targets the "main suspects" presented in the literature (namely stress, adverse emotions and anxiety), other potential mediators within this complex associations are yet to be explored. Thus for example there could be added value in exploring cognitive mediators in this association such as ruminative thinking, cognitive style, and problem solving abilities (often associated in the literature with mental and psychosomatic health, see for example: Samaie \& Farhani, 2011). Coping abilities and coping styles are only suggested indirectly in the current model and may be further researched as complementary cocnepts that may be included in more advanced versions of this model in the future.

\subsection{Potential Direction for Application and Practice}

Based on the above model and the evidence supporting EI's role in various health processes and outcomes, directions for future consideration in practice may arise. Here are just a few initial thoughts on how this model may affect how we promote health and care for individuals and groups at risk:

EI may be a useful tool for assessing risk in general and post-diagnosis risk in particular: once a diagnosis has been established-how likely is the patient to adhere with the treatment or with behavior restrictions stemming from his interventions plan? How much support or follow-up will they need (especially if they require a demanding intervention or lifestyle change)? Assessing EI at intake, or upon identification of a health risk, may be of added value to identify and follow-up individuals with lower EI as the model presented here may suggest they are at higher risk than others. Planning care, follow-up schedules and setting up support systems for patients or individuals at risk may alleviate risk, postpone morbidity and make care more effective.

Preliminary evidence suggests that EI may be especially of added value in health outcomes in chronic conditions requiring long-term adherence to treatment plans, restrictions and follow-up (e.g.: diabetes, eating disorders). Such conditions often require long term adherence to strict care schedules (e.g.: blood tests), restricted life style (dietary restrictions, for example) and more. The evidence presented and briefly reviewed here suggests that individuals with lower EI may find it more challenging to overcome frustration and discomfort, may be less likely to adhere with care schedules and plans and therefore are at higher risk of long term deterioration. Training, psycho-social intervention plans aimed at honing emotional skills (emotion regulation, postponing gratification, planning etc.) may be of added value, based on this model. Preliminary evidence may also suggest that training and recruiting "emotionally intelligence significant others", such as family or spouses of the individuals at-risk, may be of protective 
added value (e.g.: Zysberg, Bar Yoseph, \& Goldman, 2017).

As our understanding of the concept and the dynamics associating it with various health outcomes, I believe we will find ourselves dealing more and more directly with individuals' temperament and emotional world, and in doing so EI may prove to be an invaluable tool.

\section{Conflicts of Interest}

The author declares no conflicts of interest regarding the publication of this paper.

\section{References}

Austin, E. J., Saklofske, D. H., \& Egan, V. (2005). Personality, Well-Being and Health Correlates of Trait Emotional Intelligence. Personality and Individual Differences, 38, 547-558. https://doi.org/10.1016/j.paid.2004.05.009

Berkman, L. F., \& Glass, T. (2000). Social Integration, Social Networks, Social Support, and Health. Social Epidemiology, 1, 137-173.

Brackett, M. A., \& Mayer, J. D. (2003). Convergent, Discriminant, and Incremental Validity of Competing Measures of Emotional Intelligence. Personality and Social Psychology Bulletin, 29, 1147-1158. https://doi.org/10.1177/0146167203254596

Brosschot, J. F., Gerin, W., \& Thayer, J. F. (2006). The Perseverative Cognition Hypothesis: A Review of Worry, Prolonged Stress-Related Physiological Activation, and Health. Journal of Psychosomatic Research, 60, 113-124. https://doi.org/10.1016/j.jpsychores.2005.06.074

Cherniss, C., Extein, M., Goleman, D., \& Weissberg, R. P. (2006). Emotional Intelligence: What Does the Research Really Indicate? Educational Psychologist, 41, $239-245$. https://doi.org/10.1207/s15326985ep4104_4

Chiesa, A., \& Serretti, A. (2009). Mindfulness-Based Stress Reduction for Stress Management in Healthy People: A Review and Meta-Analysis. The Journal of Alternative and Complementary Medicine, 15, 593-600. https://doi.org/10.1089/acm.2008.0495

Cooper, A., \& Petrides, K. V. (2010). A Psychometric Analysis of the Trait Emotional Intelligence Questionnaire-Short Form (TEIQue-SF) Using Item Response Theory. Journal of Personality Assessment, 92, 449-457. https://doi.org/10.1080/00223891.2010.497426

DeLongis, A., Coyne, J. C., Dakof, G., Folkman, S., \& Lazarus, R. S. (1982). Relationship of Daily Hassles, Uplifts, and Major Life Events to Health Status. Health Psychology, 1, 119. https://doi.org/10.1037/0278-6133.1.2.119

Eriksson, M., \& Lindström, B. (2006). Antonovsky's Sense of Coherence Scale and the Relation with Health: A Systematic Review. Journal of Epidemiology \& Community Health, 60, 376-381. https://doi.org/10.1136/jech.2005.041616

Goleman, D. (1996). Emotional Intelligence. Why It Can Matter More than IQ. Learning, 24, 49-50.

Gustafsson, J. E. (1984). A Unifying Model for the Structure of Intellectual Abilities. Intelligence, 8, 179-203. https://doi.org/10.1016/0160-2896(84)90008-4

Johnston, V. S. (1999). Why We Feel: The Science of Human Emotions. Perseus Publishing.

Khalili, A. (2012). The Role of Emotional Intelligence in the Workplace: A Literature Re- 
view. International Journal of Management, 29, 355.

Landa, J. M. A., López-Zafra, E., Martos, M. P. B., \& del Carmen Aguilar-Luzón, M. (2008). The Relationship between Emotional Intelligence, Occupational Stress and Health in Nurses: A Questionnaire Survey. International Journal of Nursing Studies, 45, 888-901. https://doi.org/10.1016/j.ijnurstu.2007.03.005

Leventhal, H., \& Scherer, K. (1987). The Relationship of Emotion to Cognition: A Functional Approach to a Semantic Controversy. Cognition and Emotion, 1, 3-28. https://doi.org/10.1080/02699938708408361

Mäkikangas, A., Kinnunen, U., \& Feldt, T. (2004). Self-Esteem, Dispositional Optimism, and Health: Evidence from Cross-Lagged Data on Employees. Journal of Research in Personality, 38, 556-575. https://doi.org/10.1016/j.jrp.2004.02.001

Martins, A., Ramalho, N., \& Morin, E. (2010). A Comprehensive Meta-Analysis of the Relationship between Emotional Intelligence and Health. Personality and Individual Differences, 49, 554-564. https://doi.org/10.1016/j.paid.2010.05.029

Mayer, J. D., Caruso, D. R., \& Salovey, P. (1999). Emotional Intelligence Meets Traditional Standards for an Intelligence. Intelligence, 27, 267-298.

https://doi.org/10.1016/S0160-2896(99)00016-1

Mayer, J. D., Roberts, R. D., \& Barsade, S. G. (2008). Human Abilities: Emotional Intelligence. Annual Review of Psychology, 59, 507-536. https://doi.org/10.1146/annurev.psych.59.103006.093646

Morris, D., \& Bromhall, C. (1994). The Human Animal: A Personal View of the Human Species. London: BBC Books.

Nesse, R. M. (1990). Evolutionary Explanations of Emotions. Human Nature, 1, 261-289. https://doi.org/10.1007/BF02733986

Petrides, K. V. (2010). Trait Emotional Intelligence Theory. Industrial and Organizational Psychology, 3, 136-139. https://doi.org/10.1111/j.1754-9434.2010.01213.x

Petrides, K. V., \& Furnham, A. (2001). Trait Emotional Intelligence: Psychometric Investigation with Reference to Established Trait Taxonomies. European Journal of Personality, 15, 425-448. https://doi.org/10.1002/per.416

Samaie, G., \& Farahani, H. A. (2011). Self-Compassion as a Moderator of the Relationship between Rumination, Self-Reflection and Stress. Procedia-Social and Behavioral Sciences, 30, 978-982. https://doi.org/10.1016/j.sbspro.2011.10.190

Sanchez-Alvarez, N., Extremera, N., \& Fernández-Berrocal, P. (2016). The Relation between Emotional Intelligence and Subjective Well-Being: A Meta-Analytic Investigation. The Journal of Positive Psychology, 11, 276-285.

https://doi.org/10.1080/17439760.2015.1058968

Schutte, M. J., Ree, M. J., \& Carretta, T. R. (2004). Emotional Intelligence: Not Much more than G and Personality. Personality and Individual Differences, 37, 1059-1068. https://doi.org/10.1016/j.paid.2003.11.014

Schutte, N. S., Malouff, J. M., Thorsteinsson, E. B., Bhullar, N., \& Rooke, S. E. (2007). A Meta-Analytic Investigation of the Relationship between Emotional Intelligence and Health. Personality and Individual Differences, 42, 921-933. https://doi.org/10.1016/j.paid.2006.09.003

Sternberg, E. M. (2001). The Balance within: The Science Connecting Health and Emotions. New York, NY: Macmillan.

Stough, C., Saklofske, D. H., \& Parker, J. D. (2009). A Brief Analysis of 20 Years of Emotional Intelligence: An Introduction to Assessing Emotional Intelligence: Theory, Research, and Applications. In Assessing Emotional Intelligence (pp. 3-8). Boston, MA: 
Springer. https://doi.org/10.1007/978-0-387-88370-0_1

Thorndike, R. K. (1920). Intelligence and Its Uses. Harper's Magazine, 140, 227-335.

Zysberg, L. (2016). Diabetic Management and Emotional Intelligence-An Emerging Direction in Current Research. Journal of Endocrinology and Diabetes, 3, 1-3.

https://doi.org/10.15226/2374-6890/3/2/00145

Zysberg, L. (2017). Emotional Intelligence and Health Outcomes: Toward an Ecological Model of Well-Being. New York, NY: Nova.

Zysberg, L. (2017b). Emotional Intelligence Moderates Anxiety Reactions in Chronic Health Conditions. American Journal of Applied Psychology, 6, 38-41.

https://doi.org/10.11648/j.ajap.20170603.12

Zysberg, L., Bar Yoseph, T., \& Goldman, M. (2017). Emotional Intelligence and Glycemic Management among Type I Diabetes Patients. Journal of Health Psychology, 22, 158-163. https://doi.org/10.1177/1359105315596373 